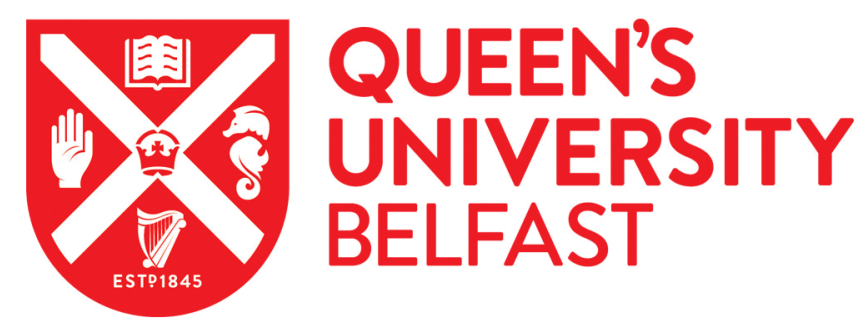

\title{
Estimating the population exposed to arsenic from groundwater- sourced private drinking water supplies in Cornwall, UK
}

Crabbe, H., Close, R., Rimell, A., Leonardi, G., Watts, M. J., Ander, E. L., Hamilton, E. M., Middleton, D. R. S., Smedley, P. L., Gregory, M., Robjohns, S., Sepai, O., Studden, M., Polya, D. A., \& Fletcher, T. (2017).

Estimating the population exposed to arsenic from groundwater-sourced private drinking water supplies in Cornwall, UK. In P. Bhattacharya, D. A. Polya, \& D. Jovanovic (Eds.), Best Practice Guide on the Control of Arsenic in Drinking Water (pp. 161-170). IWA Publishing. https://doi.org/10.2166/9781780404929_161

Published in:

Best Practice Guide on the Control of Arsenic in Drinking Water

\section{Document Version:}

Publisher's PDF, also known as Version of record

\section{Queen's University Belfast - Research Portal:}

Link to publication record in Queen's University Belfast Research Portal

\section{Publisher rights}

Copyright 2017 the authors.

This is an open access article published under a Creative Commons Attribution-NonCommercial-ShareAlike License

(https://creativecommons.org/licenses/by-nc-sa/4.0/), which permits use, distribution and reproduction for non-commercial purposes, provided the author and source are cited and new creations are licensed under the identical terms.

\section{General rights}

Copyright for the publications made accessible via the Queen's University Belfast Research Portal is retained by the author(s) and / or other copyright owners and it is a condition of accessing these publications that users recognise and abide by the legal requirements associated with these rights.

\section{Take down policy}

The Research Portal is Queen's institutional repository that provides access to Queen's research output. Every effort has been made to ensure that content in the Research Portal does not infringe any person's rights, or applicable UK laws. If you discover content in the Research Portal that you believe breaches copyright or violates any law, please contact openaccess@qub.ac.uk. 


\section{Chapter A3}

\section{Estimating the population exposed to arsenic from groundwater-sourced private drinking water supplies in Cornwall, UK}

Helen Crabbe ${ }^{1 *}$, Rebecca Close ${ }^{1}$, Amy Rimell' ${ }^{1}$, Giovanni Leonardi1,2, Michael J. Watts ${ }^{3 a}$, E. Louise Ander ${ }^{3 a}$, Elliott M. Hamilton ${ }^{3 a}$, Daniel R. S. Middleton ${ }^{1,3 a, 4}$, Pauline L. Smedley ${ }^{3 b}$, Martin Gregory ${ }^{5}$, Stephen Robjohns ${ }^{1}$, Ovnair Sepai ${ }^{1}$, Mike Studden ${ }^{1}$, David A. Polya ${ }^{4}$ and Tony Fletcher ${ }^{1,2}$

${ }^{1}$ Centre for Radiation, Chemicals and Environmental Hazards, Public Health England, Chilton, Didcot, UK; OX11 ORQ, United Kingdom

2London School of Hygiene and Tropical Medicine, London, WC1E 7HT, United Kingdom

3aInorganic Geochemistry, Centre for Environmental Geochemistry; ${ }^{3 b}$ Groundwater Science, British Geological Survey, Keyworth, Nottingham, NG12 5GG, United Kingdom

${ }^{4}$ School of Earth and Environmental Sciences and Williamson Research Centre for Molecular Environmental Science, The University of Manchester, Manchester, M13 9PL, United Kingdom

${ }^{5}$ Cornwall Council, Environmental Protection Team, Public Health and Protection, Camborne, Cornwall, TR14 8SX, United Kingdom

${ }^{*}$ Corresponding author: helen.crabbe@phe.gov.uk

\section{A3.1 INTRODUCTION}

Where connection to mains public supplies is not available, or not utilized, a large number of people worldwide rely on groundwater for drinking water through private water supplies (PWS). Chronic exposure to chemicals in PWS may have an adverse effect on health. Many areas of the world, perhaps most notably Bangladesh, are known to have elevated concentrations of arsenic in groundwater used for drinking or cooking (Ayotte et al. 2003; Henke, 2009; Murcott, 2012; Polya \& Lawson, 2015). Such occurrences, albeit

(C) 2017 The Author(s) This is an Open Access book chapter distributed under the terms of the Creative Commons Attribution Licence (CC BY-NC-SA 4.0), which permits copying and redistribution for non-commercial purposes, provided the original work is properly cited and that any new works are made available on the same conditions (http://creativecommons.org/licenses/by-nc-sa/4.0/). This does not affect the rights licensed or assigned from any third party in this book. The chapter is from the book Best Practice Guide on the Control of Arsenic in Drinking Water, Prosun Bhattacharya, David A. Polya and Dragana Jovanovic (Eds.).

DOI: 10.2166/9781780404929_161 
at often lower concentrations, have also been documented in the European Union (Kurttio et al. 1999; Varsanyi \& Kovacs, 2006; Lindberg et al. 2006; Hough et al. 2010; Jovanovic, 2017) including in the UK and in particular in Cornwall (Ander et al. 2016) in the South West of England (Figure A3.1). Elevated arsenic concentrations in groundwater are thought to be causally associated with natural mineralisation and the human exploitation of mineral resources. However, notwithstanding the documented detrimental health effects arising from chronic exposure to arsenic in untreated or inadequately treated PWS, there remains uncertainty as to the precise extent of the population substantially exposed both in Cornwall and in many other parts of the European Union. This is due to the variability in the completeness of PWS records and the complexity of the arrangements for the collection and collation of such data.

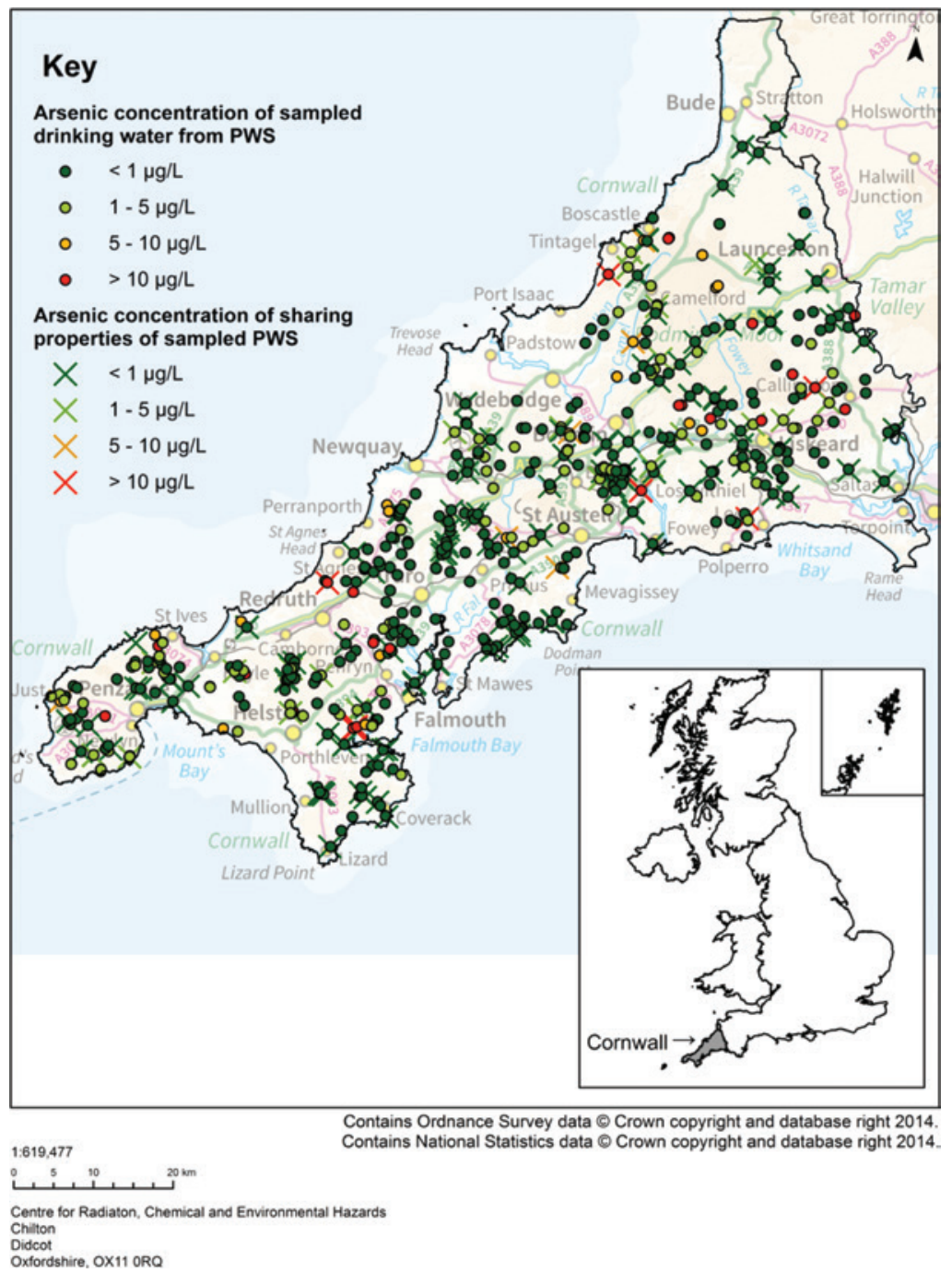

Figure A3.1 Private water supplies sampled in Cornwall, along with location of shared supplies and arsenic concentrations. 
We report here a case study of a recent (2011-2013) sampling and analysis programme of PWS in Cornwall and, in particular, (i) estimates of the population exposed to arsenic from PWS in Cornwall and (ii) estimated distribution of PWS arsenic exposures to that population. We estimate the number of people potentially exposed to arsenic above the Prescribed Concentration or Value (PCV) required by national Regulations (Drinking Water Inspectorate (DWI), 2009), which was implemented from the EU Directive 98/83/EC (Council of the European Union, 1998) and the WHO guideline value (WHO, 2011a) of $10 \mu \mathrm{g} / \mathrm{L}$. The potential health effects of arsenic exposure and a process for communication of risks to users is also outlined.

\section{A3.2 METHODS}

\section{A3.2.1 Recruitment of households with PWS}

The existing list of households known to use PWS was provided in late 2010 by Cornwall Council and used for two field campaigns, east Cornwall (2011) and west Cornwall (2013). Households were targeted where it was known that they had a groundwater source (borehole, spring capture or traditional large-diameter well), serving a PWS. Properties using public supplies, PWS surface water sources, or not using the PWS for domestic drinking water were excluded. Larger PWS serving businesses were also excluded. A total of 3095 records were retained. There were $33(1 \%)$ records removed due to the use of surface water, rather than groundwater, for the PWS. Some records were incomplete, and these were clarified on contact with potential volunteer householders to ensure that the PWS met the study design criteria.

A stratified, random design was used: records were classified into one of 10 geological categories, within which the records were randomised for sequence of contacting. It is, however, important to note that participation was entirely on a voluntary basis.

Where contact details of residents were incomplete (37\%), these were amended by searching the council records (e.g. environmental health records, council tax records), the electoral roll and telephone or other online directories: where a valid address could not be established the record could not be used $(\sim 30 \%$ of records). Contact was made by letter ( $>2000$ in total) and follow-up phone call to ensure adequate recruitment. In east Cornwall a local newspaper advertisement was also used.

Householders were encouraged to participate by the provision of the measured chemical data for their property, free-of-charge. After a two week recruitment drive for each phase, 497 households volunteered for the study and had their PWS drinking water sampled in spring (March/April) 2011 and 2013. A further fifteen properties were sampled when householders were absent in 2011, leading to ambiguity in knowing the extent of treatment used in water serving exterior taps: this was avoided in 2013 sampling. These data were not used as drinking water samples.

On recruitment, the head of the household and/or PWS owner were asked a series of questions by telephone, about the nature of the water supply, water treatment methods, the number of people living in the property and the number of properties the supply served. From this, the total number of residents served by the sampled PWS and the total number of properties served by the sampled PWS was calculated.

Further sampling design and chemical data collection methods are detailed in Ander et al. (2016). There were 497 samples taken to assess the chemical quality of drinking water from groundwater-sourced PWS (Figure A3.1).

\section{A3.2.2 Estimating the number of PWS and residents served in Cornwall}

The exact number of PWS in Cornwall serving domestic properties is not known. The most recent record of domestic PWS currently registered in Cornwall $(n=2995)$ was used (DWI, 2015) as a starting basis. This was considered a more up-to-date assessment originating from Cornwall Council than the database 
version used in the original study planning. The average number of residents per household was calculated on a pro rata basis using the telephone householder questionnaires. These were also the source for information on numbers of further domestic properties served by a PWS source.

There were a number of households which also ran businesses with temporary residents on their property (caravan sites, holiday lets, holiday bed and breakfast). Only permanent residents at these sites were included in this assessment.

\section{A3.2.3 Estimating the population exposed to arsenic in PWS}

The distribution of arsenic concentrations in the surveyed tap water samples (Ander et al. 2016) was applied to the modelled number of PWS and the residential population served in Cornwall.

\section{A3.3 RESULTS}

\section{A3.3.1 Estimating the number of PWS residents included in the survey}

From the telephone recruitment questionnaire, it is known that 1263 residents were served by the PWS, at $94 \%(n=467)$ of the sampled households, giving an average of 2.7 individuals per household. Using a Geographical Information System (GIS) and the National Population Database (NPD) (HSL, 2015) shapefile, we estimate that an additional 81 people are likely to live in the 30 households $(6 \%)$ for which we do not have records, giving a total of 1344 residents served by the sampled PWS. This average occupancy rate is higher than the 2011 Census data (mean 2.3) (Cornwall Council, 2012).

In this study, $62 \%(n=308)$ of households were the only users of the PWS, with $31 \%(n=154)$ sharing their supply with other properties, based on questionnaire responses (7\% not known). We found a higher proportion of small shared supplies than the DWI estimate of $14 \%(\mathrm{n}=533)$ on shared supplies $(\mathrm{z}$ score test shows a difference in the proportions, $\mathrm{p}<0.001$ ).

The shared supplies provide a further 352 households, in addition to the 154 which were sampled, using telephone questionnaire responses $(n=126)$ and otherwise estimated using GIS (Figure A3.2). We predict these contained 950 residents. Thus 849 properties are estimated to have 2294 people using drinking water from the PWS that we sampled.

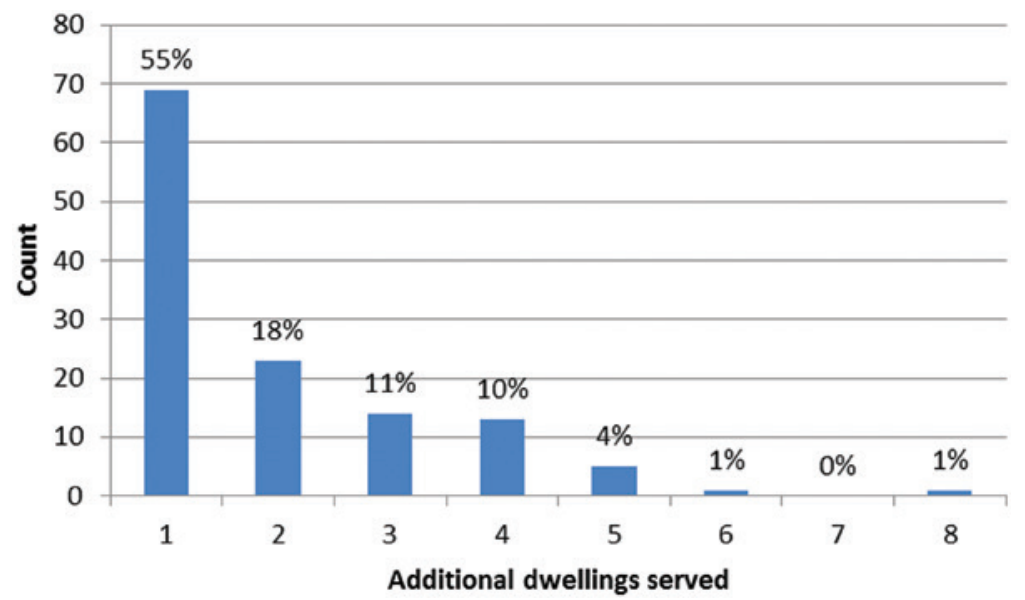

Figure A3.2 Distribution of the number of additional dwellings served by the sampled PWS in Cornwall (data available for 126 PWS). 


\section{A3.3.2 Estimated Cornish population using PWS, from official records}

The DWI (2015) estimated that there are some 37,717 PWS in England, of which 67\% (25,270) serve a single household, known as 'Single Domestic Dwellings' (SDDW). In Cornwall 65\% ( $\mathrm{n}=2462)$ are recorded as SDDW PWS.

DWI (2015) estimated that $5.25 \%$ of the population in Cornwall are served by 3811 PWS, considering all types of PWS. Given a total population of 545,335 in 2014 (ONS, 2015a), this implies 28,630 people are drinking water from PWS. Using the ONS Rural Urban Classification of land use (ONS, 2015b), we find that $97 \%$ of sampled PWS were in rural hamlets $(77 \%)$ or rural villages $(20 \%)$, with the remainder in more urban settings. The total Cornish population (2011 Census) for these rural hamlet and village areas was 182,655 , implying that $16 \%$ of the population in these settings may be using PWS.

\section{A3.3.3 Estimating the population exposure distribution to drinking water arsenic}

The number of households that exceeded the PCV $(10 \mu \mathrm{g} / \mathrm{L})$ for arsenic was 27 (5.4\%). These served 66 residents and it was known that 15 additional properties (serving 21 people) also shared these PWS, giving 87 users. We assume that their drinking water concentrations are identical to that of the sampled property, and not affected in any way by individual household treatment which may be installed. We also calculate the residents potentially exposed to arsenic categories of $<1,1-5,5-10$ and $>10 \mu \mathrm{g} / \mathrm{L}$ by the same method.

Of the 28,630 people estimated to be using PWS drinking water in Cornwall, and assuming 5.4\% exceeding the As PCV, we infer that there could be approximately 1,432 residents in Cornwall using tap water which exceeds the As PCV. Caveats in this calculation include the assumption that only a negligible proportion of PWS are not sourced from groundwater, and the (unquantified) uncertainty on the 5.25\% estimate of the population using PWS in Cornwall. Applying the As concentration distribution found in the 497 samples to the wider population calculated to be using PWS, Table A3.1 summarises the number of households and people predicted to be exposed to varying levels of arsenic measured in the PWS in Cornwall.

Table A3.1 Distribution of arsenic concentrations and number of exposed residents and households modelled (based on NPD and DWI PWS data). The PCV for arsenic is $10 \mu \mathrm{g} / \mathrm{L}$.

\begin{tabular}{llcc}
\hline $\begin{array}{l}\text { Arsenic Concentration } \\
\text { Range } \\
(\mu \mathrm{g} / \mathrm{L})\end{array}$ & $\begin{array}{l}\text { Proportion of } \\
\text { Total Groundwater } \\
\text { Supplied PWS (\%) }\end{array}$ & $\begin{array}{l}\text { Predicted Number } \\
\text { of Households }\end{array}$ & $\begin{array}{l}\text { Predicted Number } \\
\text { of Residents }\end{array}$ \\
\hline$<1$ & 71 & 7650 & 20,327 \\
$1-5$ & 20 & 2155 & 5726 \\
$5-10$ & 4 & 431 & 1145 \\
$>10$ & 5 & 539 & 1432 \\
Total & $100 \%$ & $\mathbf{1 0 , 7 7 4}$ & $\mathbf{2 8 , 6 3 0}$ \\
\hline
\end{tabular}

\section{A3.4 DISCUSSION}

\section{A3.4.1 Guideline values, standards and health effects of arsenic in drinking water}

The UK PCV (2009) and WHO (2011a) provisional drinking water guideline value for arsenic of $10 \mu \mathrm{g} / \mathrm{L}$ is set to protect health. Long-term (many years) exposure to relatively high arsenic drinking water levels 
can produce skin lesions (e.g. hyperpigmentation and hypopigmentation), peripheral vascular disease, peripheral neuropathy and an increased risk of skin, lung and bladder cancer (HPA, 2011; WHO, 2011b). The International Agency for Research on Cancer (IARC) determined that long term exposure to inorganic arsenic (the form most commonly found in water) can cause cancer of the lung, skin and bladder (IARC, 1987, 2004, 2012; WHO, 2011b). The WHO consider that it is not possible to identify a level of exposure to arsenic that is completely free from cancer risk and Leonardi et al. (2012) suggest possible detrimental health impacts arising from chronic exposure through drinking water with sub-PCV concentrations. Therefore, exposure to inorganic arsenic from drinking water should be as low as reasonably practicable (ALARP) (WHO, 2011a).

Arsenic accumulates in the placenta where it may impair function and lead to a reduction in the efficiency of nutrient transport to the foetus. Additionally, it can cross the placenta and may then cause toxic effects (UKTIS, 2012). There is some evidence that arsenic exposure to the unborn baby or infants may adversely affect the developing nervous system (e.g. impaired cognitive functions, such as learning and memory) and lead to reduced birthweight (EFSA, 2009). Therefore, Public Health England (PHE) advises that women who are pregnant should avoid drinking water containing arsenic at levels above the UK PCV (updated advice from HPA, 2011).

\section{A3.4.2 Public health advice given to households with exceedances}

For any households that had one or more exceedance of PCVs, PHE and Cornwall Council sent chemical specific advice in the form of public health advice sheets. This was sent alongside the results of the chemical testing that summarised the main sources of the contaminant, outlined the potential acute and chronic health effects, and suggested action to be taken to reduce exposure to the contaminant [see for example http://www.bgs.ac.uk/sciencefacilities/laboratories/geochemistry/igf/Biomonitoring/arsenicSW. html]. The local authority supported with advice on mitigation measures to reduce arsenic concentrations in PWS.

The advice given to households with arsenic exceedance included some immediate, precautionary, health advice that included the following:

- Recommendation to avoid drinking and cooking with tap water containing arsenic above the PCV on a long-term basis.

- Pregnant women should avoid drinking water containing arsenic above the PCV.

- For any exceedances found, further testing was advised as there are different factors such as seasonal variation (particularly wet or dry months) that could affect the results. If the results further exceed the PCV, PHE recommended not drinking or cooking with the PWS tap water on a long-term basis.

The advice to anyone who had been regularly consuming water from the affected supply and had adverse effects consistent with excessive arsenic consumption was to seek advice from their general medical practitioner (GP). GPs were also sent briefings to advise them of the sampling programme and advised to seek specialist clinical toxicological advice from the National Poisons Information Service (NPIS, 2015).

The results of the water testing were sent back to the householders via letters, along with the advice sheets and any high or excessive exceedances were individually followed up with phone calls to raise awareness of the problem and advise of action to take.

The majority of enquiries received from the feedback of results were regarding what action to take and seeking assurance of the health risk posed. When a subset of households were contacted a year later, asking if they would take part in a follow-on biomonitoring study (Middleton et al. 2016a, 2016b), feedback was 
gained on the actions they had taken following the results of the water testing. Some households had taken action on the advice given; undertaking maintenance of treatment systems or switching to bottled water for drinking, whilst others hadn't.

\section{A3.4.3 Evaluating arsenic PCV exceedances}

Between 2010 and 2014, the DWI reported that 5.6\% (14/249) of arsenic tests on SDDW in England failed the PCV (DWI, 2015). This is comparable to our overall study finding 5.4\% failure in Cornwall alone. In this study, a substantial number of PWS shared the supply with other properties (31\%), greatly increasing the number of residents served by these supplies.

DWI (2015) estimated that $5.25 \%$ of the population in Cornwall are served by private supplies, including larger shared supplies - using that value would appear to indicate $\sim 10,800$ properties with PWS (based on 28,630 users and an average household occupancy of 2.7), a somewhat higher figure than the $\sim 3100$ number on the register). There is anecdotal information that these records may be incomplete, particularly for the SDDW properties, probably because SDDW are not required to risk assess and monitor the PWS being used (DWI, 2009). In Northern Ireland (NI), where 99\% of PWS are from groundwater, records of SDDW $(\mathrm{n}=128)$ were an under-representation by $\sim 1,100$ properties, as calculated by subtraction of the known public and private supplies from the total households in NI (DWINI, 2014). These unregistered PWS were thought to be SDDW. The numerical inconsistencies and the DWINI report indicate the potential scale of the knowledge gap in relation to domestic use of PWS.

\section{A3.4.4 Representativeness of samples and caveats}

Drinking water samples were collected from 497 household PWS, approximately 17\% of the $\sim 3100$ households on the original public register. Visits to households took place in the day, from 08:00 to 18:00, with some appointments available in the evenings and through the weekend to allow for the working population. There may be over-representation of older people in this survey, perhaps influenced by their more flexible availability for appointments, as was seen in the follow-up biomonitoring study (Middleton et al, 2016a,b). Business and commercial users of PWS were excluded from the study, unless they used a PWS for domestic drinking water.

In west Cornwall in 2013, $12 \%$ of households declined to take part when invited. The reasons for refusal included:

- The resident had their PWS tested regularly and therefore didn't think it was necessary to have an additional sample taken.

- The resident didn't want the additional hassle of having their PWS sampled (not convenient).

- The resident was not available during the water sampling programme.

- The resident did not use their PWS for drinking, but used mains water instead.

Similar reasons were given for refusal in east Cornwall in 2011.

Representativeness of the sample is reflected in our recruitment methods; based on the characteristics of recruited households, such as householders being retired or working, household size, number of shared supplies, land use classification, property type and geological classification. Characteristics of un-recruited households may differ in terms of these parameters.

Bias may occur through our recruitment methods. We could only contact and invite households if they were known to have a PWS, and if their details were up to date or known to various directories or council sources. Recruitment stopped when all appointment slots were booked. Householders less concerned with the quality of their supplies, or not wishing to be on an official register, may not have responded to the 
invite. The sample size depended upon the budget and resources available to the sampling team. It was necessary for householders to be available within the sampling programme or otherwise provide consent for access to their PWS and/or tap water supply. A small proportion of households were sampled as a result of meeting field teams on-site or word of mouth between neighbours, for which many of these were not on the central register.

The estimates of population exposure depended upon the accuracy of the source data, although DWI estimates are summaries of data reported by each council annually. Information on the number of residents per property depended upon residents reporting true occupancy in the questionnaire. The NPD is modelled on census returns and $a d-h o c$ administrative surveys. Both can be subject to reporting biases and inaccuracies. Information on shared supplies depended upon respondents giving accurate responses to the questionnaire. There were some missing data in the form of non-response or 'not known' for some questions. Some inaccuracies were recorded as the water treatment method was unknown or incorrectly stated by the householder, as validated by the field notes taken by BGS at the time of visits against resulting data (Ander et al. 2016).

\section{A3.5 CONCLUSIONS}

A survey of 497 households in Cornwall between 2011 and 2013, recorded 5.4\% of households to be utilising drinking water from PWS with arsenic concentrations exceeding the PCV of $10 \mu \mathrm{g} / \mathrm{L}$. A further $4 \%$ of households recorded PWS arsenic concentrations between 5 and $10 \mu \mathrm{g} / \mathrm{L}$, whilst $30 \%$ of households had PWS arsenic concentrations above $1 \mu \mathrm{g} / \mathrm{L}$.

On the basis of a representative PWS population sampled in Cornwall, an estimation of the total population in Cornwall utilising PWS for drinking water was calculated to inform the distribution of the population exposed to $1,5-10$ and $10 \mu \mathrm{g} / \mathrm{L}$ arsenic in their PWS drinking water. Private water drinking supply user estimates and surveyed PWS arsenic concentrations indicated that approximately 1432 people in Cornwall are likely to be chronically exposed to arsenic through their PWS at concentrations exceeding the PCV of $10 \mu \mathrm{g} / \mathrm{L}$; a further 1145 are likely to be exposed at concentrations between 5 and $10 \mu \mathrm{g} / \mathrm{L}$ and a likely total of over 20,300 exposed at concentrations above $1 \mu \mathrm{g} / \mathrm{L}$. Public health advice sheets were prepared to outline the chronic risks of drinking water with elevated arsenic. Householders were sent advice if their water exceeded the PCVs. Cornwall Council continue to risk assess PWSs and recommend or enforce remediation where appropriate. In identifying the risk of arsenic the intention is to communicate the risk to those affected and local communities. It is hoped that in the future where similar situations arise, local authorities could utilise the advice sheets as a resource to highlight the risks to PWS users.

This work highlights the importance of testing for arsenic in SDDW and shared PWS particularly in areas of high geological risk. Further research is being carried out to more accurately estimate the population exposure from biomonitoring samples provided by a subset of these PWS householders and will be the subject of further publications (e.g. Middleton et al. 2016a,b). This work can inform the risk assessment of consumption from PWS and in the planning and implementation of public health prevention strategies. Further information on the project is available from:

http://www.bgs.ac.uk/sciencefacilities/laboratories/geochemistry/igf/Biomonitoring/arsenicSW.html

\section{A3.6 ACKNOWLEDGEMENTS}

The authors would like to thank all the householders who participated in the study. PHE colleagues are thanked for their support and input including the South West PHE Centre for field work co-ordination, recruitment of households and project management. Public health students also helped to recruit householders 
to the study. Allister Gittins of PHE conducted some GIS analysis to prepare Cornwall specific population datasets. Neville Verlander of PHE provided statistical advice. We thank Cornwall Council Environmental Protection Team for access to the public register of private water supplies, and for dissemination of results and advice to householders. PHE funded the study design, field collection and analysis within the Environmental Public Health Tracking programme. DM was funded by NERC through a UoM/BGS joint PhD studentship (Contract No. GA/125/017, BUFI Ref: S204.2). All other costs were met by the authors' organisations.

\section{A3.7 REFERENCES}

Ander E. L., Watts M. J., Smedley P. L., Hamilton E. M., Close R., Crabbe H., Fletcher T., Studden M., Rimell A. and Leonardi G. (2016). Variability in private drinking water supply chemistry, and the impact of domestic treatment systems on water quality. Environmental Geochemistry and Health, DOI: 10.1007/s10653-016-9798-0.

Ayotte J., Montgomery S., Flanagan S. and Robinson K. (2003). Arsenic in Groundwater in Eastern New England: Occurrence, Controls, and Human Health Implications. Environmental Science and Technology, 37, 2075-2083.

Cornwall Council (2012). 2011 Census, at a glance (First Release), July 2012 https://www.cornwall.gov.uk/media/ 3624040/Census_at_a_glance_1stRelease.pdf

Council of the European Union (1998). The quality of water intended for human consumption. Council Directive 98/83/EC. Available at: http://ec.europa.eu/environment/water/water-drink/legislation_en.html

Drinking Water Inspectorate (DWI) (2009). Drinking water safety - Guidance to health and water professionals. http://www.dwi.gov.uk/stakeholders/information-letters/2009/09_2009Annex.pdf

Drinking Water Inspectorate (2015). Drinking water 2014: Private water supplies in England, July 2015. http://dwi. defra.gov.uk/about/annual-report/2014/pws-eng.pdf

Drinking Water Inspectorate for Northern Ireland (DWINI) (2014). Drinking water quality in Northern Ireland, 2013. Northern Ireland Environment Agency, Belfast. ISBN: 978-1-907053-73-3.

EFSA (European Food Safety Authority) (2009). Panel on Contaminants in the Food Chain (CONTAM), Scientific Opinion on Arsenic in Food. EFSA Journal, 7(10), 1351. Available at: http://www.efsa.europa.eu/sites/default/ files/scientific_output/files/main_documents/1351.pdf

Health and Safety Laboratory (HSL) (2015). National Population Database: http://www.hsl.gov.uk/resources/ health-safety-insights/a-tool-for-uk-contingency-planning

HPA (now PHE) (2011). Compendium of Chemical Hazards: Arsenic. Available at: https://www.gov.uk/government/ uploads/system/uploads/attachment_data/file/316730/Compendium_of_Chemical_Hazards_ARSENIC_v4-1.pdf

Henke K. R. (ed.) (2009). Arsenic. John Wiley and Sons. DOI: 10.1002/9780470741122.

Hough R. L., Fletcher T., Leonardi G. S., Goessler W., Gnagnarella P., Clemens F., Gurzau E., Koppova K., Rudnai P., Kumar R. and Vahter M. (2010). Lifetime exposure to arsenic in residential drinking water in Central Europe. International Archives of Occupational and Environmental Health, 83, 471-481.

International Agency for Research on Cancer (1987). Overall Evaluations of Carcinogenicity: an updating of IARC Monographs 1-42. IARC Monographs; http://monographs.iarc.fr/ENG/Monographs/suppl7/suppl7.pdf

International Agency for Research on Cancer (2004). Arsenic in drinking-water. IARC Monographs on the Evaluation of Carcinogenic Risks to Humans, Volume 84.

International Agency for Research on Cancer (2012). Arsenic and arsenic compounds. IARC Monographs on the Evaluation of Carcinogenic Risks to Humans, Volume 100C, pp. 41-93; http://monographs.iarc.fr/ENG/ Monographs/vol100C/mono100C-6.pdf

Jovanovic D. (2017). Public health effects of arsenic exposure. In: Best Practice Guide on the Control of Arsenic in Drinking Water, P. Bhattacharya, D. Jovanovic and D. A. Polya (eds), IWA Publishing. This volume.

Kurttio P., Pukkala E., Kahelin H., Auvinen A. and Pekkanen J. (1999). Arsenic concentrations in well water and risk of bladder and kidney cancer in Finland. Environmental Health Perspectives, 107, 705-710.

Leonardi G., Vahter M., Clemens F., Goessler W., Gurzau E., Hemminki K., Hough R., Koppova K., Kumar R., Rudnai P., Surdu S. and Fletcher T. (2012). Inorganic Arsenic and Basal Cell Carcinoma in Areas of Hungary, Romania, and Slovakia: A Case-Control Study. Environmental Health Perspectives, 120, 721-726. 
Lindberg A. L., Goessler W., Gurzau E., Koppova K., Rudnai P., Kumar R., Fletcher T., Leonardi G., Slotova K., Gheorghiu E. and Vahter M. (2006). Arsenic exposure in Hungary, Romania and Slovakia. Journal of Environmental Monitoring, 8, 203-208.

Middleton D. R. S., Watts M. J., Hamilton E. M., Ander E. L., Close R. M., Exley K. S., Crabbe H., Leonardi G. S., Fletcher T. and Polya D. A. (2016a). Urinary arsenic profiles reveal exposures to inorganic arsenic from private drinking water supplies in Cornwall, UK. Scientific Reports, 6, Article 25656.

Middleton D. R. S., Watts M. J., Hamilton E. M., Fletcher T., Leonardi G. S., Close R. M., Exley K. S., Crabbe H. and Polya D. A. (2016b). Prolonged exposure to arsenic in UK private water supplies: toenail, hair and drinking water concentrations. Environmental Science: Processes and Impacts, 18, 562-574.

Murcott S. (2012). Arsenic Contamination in the World: An International Sourcebook. IWA Publishing. ISBN13: 9781780400389.

National Poisons Information Service (NPIS) (2015). Available at http://www.npis.org/

ONS (Office of National Statistics) (2015a). Mid-year population estimates for Cornwall. Available from http:// www.ons.gov.uk/ons/rel/pop-estimate/population-estimates-for-uk-england-and-wales-scotland-and-northernireland/mid-2014/stb—mid-2014-uk-population-estimates.html

ONS (Office of National Statistics) (2015b). Rural Urban Classification of land use (based on Census 2011) https:// www.gov.uk/government/collections/rural-urban-definition

Polya D. A. and Lawson M. (2015). Geogenic and anthropogenic arsenic hazard in groundwaters and soils distribution, nature, origin \& human exposure routes. In: Arsenic: Exposure Sources, Health Risks, and Mechanisms of Toxicity, J. C. States (ed.), Wiley. ISBN: 978-1-118-51114-5; Chapter 2, pp. 34-114.

Private Water Supplies Regulations (2009). SI 3101; http://dwi.defra.gov.uk/stakeholders/legislation/pwsregs2009.pdf Varsanyi I. and Kovacs L. O. (2006). Arsenic, iron and organic matter in sediments and groundwater in the Pannonian Basin, Hungary. Applied Geochemistry, 21, 949-963.

UK Teratology Information Service (UKTIS) (2012). Exposure to Arsenic in Pregnancy, in UKTIS Annual Report: Available at: http://www.uktis.org/docs/Annual\%20Report-2012-2013.pdf\#search=\%22annual report\%22

World Health Organization (WHO) (2011a). Guidelines for Drinking-water Quality, 4th edn, http://whqlibdoc.who. int/publications/2011/9789241548151_eng.pdf?ua=1

World Health Organization (WHO) (2011b). Arsenic in Drinking-water. Background document for development of WHO Guidelines for Drinking-water Quality. Available at: http://www.who.int/water_sanitation_health/dwq/ chemicals/arsenic.pdf?ua $=1$ 